\title{
A ação conjunta dos profissionais da saúde e da educação na escola inclusiva*
}

\section{Health and education professionals partnership in inclusive edu,cation}

\author{
Miryam Bonadiu Pelosi', Leila Regina D’Oliveira de Paula Nunes ${ }^{2}$
}

PELOSI, M. B.; NUNES, L. R. D. P. A ação conjunta dos profissionais da saúde e da educação na escola inclusiva. Rev. Ter. Ocup. Univ. São Paulo, v. 22, n. 1, p. 52-59, jan./abr. 2011.

\begin{abstract}
RESUMO: O objetivo do estudo foi avaliar se a introdução da Tecnologia Assistiva favorece a inclusão de alunos com paralisia cerebral em quatro escolas regulares do município do Rio de Janeiro quando esta é mediada pela ação conjunta de profissionais da Saúde e Educação. Participaram do estudo quatorze professores itinerantes, cinco terapeutas ocupacionais, três fonoaudiólogas, quatro diretores, quatro alunos com paralisia cerebral e seus familiares, quatro professores de turma e cinco professores de aulas complementares. O modelo do estudo foi a pesquisa-ação e os instrumentos compreenderam questionários, entrevistas semi-estruturadas, registros dos participantes, fotografias, filmes e o caderno de campo da pesquisadora. Foram formadas quatro equipes constituídas por terapeutas ocupacionais, fonoaudiólogos e professores itinerantes que haviam recebido formação em serviço na área de tecnologia assistiva. Esses profissionais foram à escola com a freqüência de quatro a seis encontros e participaram de sete supervisões fora do espaço educacional. Os resultados da ação conjunta compreenderam situações de aprendizagem favoráveis à inclusão escolar; sensibilização e mudança de atitude dos professores, e aproximação de professores e alunos. O emprego sistemático de recursos de tecnologia assistiva teve efeitos positivos na postura dos alunos em sala de aula, no desenvolvimento de estratégias alternativas de comunicação oral e escrita, no aumento da mobilidade dos alunos através do uso de cadeiras de rodas apropriadas e na independência para as atividades do dia-a-dia escolar.
\end{abstract}

DESCRITORES: Terapia ocupacional; Paralisia cerebral; Educação continuada.

\footnotetext{
* O estudo compõe a tese de doutorado financiada pelo CNPq e FAPERJ intitulada: Inclusão e Tecnologia Assistiva defendida pela primeira autora em março de 2008 no Programa de Pós-Graduação em Educação da Faculdade de Educação da Universidade do Estado do Rio de Janeiro (Pelosi, 2008).

1. Terapeuta Ocupacional, PhD. em Educação. Profa. adjunta do Curso de Terapia Ocupacional Universidade Federal do Rio de Janeiro .

2. Ph.D. em Educação Especial, Programa de Pós-Graduação em Educação Universidade do Estado do Rio de Janeiro.

Endereço para correspondência: Miryam Bonadiu Pelosi. Av. dos Flamboyants, 1250, Bloco 1, Ap.505. rra da Tijuca. Rio de Janeiro RJ. CEP: 22776-070. e-mail: miryam.pelosi@gmail.com
} 


\section{INTRODUÇÃO}

cada ano mais crianças com necessidades
educacionais especiais estão sendo incluídas
nas escolas. Essa nova escola acolhe e ensina pessoas respeitando as diferenças individuais, raciais, políticas, religiosas, sociais e/ou culturais. Trata-se de uma escola mais responsiva às necessidades do alunado e que forma seus professores para auxiliá-los a ensinar todos os alunos e, não apenas, os considerados com necessidades educacionais especiais (MITTLER, 2003).

Para que possa atender a diversidade de alunos dessa nova escola é preciso criar uma rede de apoio composta por pessoas que se reúnam para debater idéias, resolver problemas e compartilhar conhecimento sobre métodos, técnicas e atividades que auxiliem professores e alunos a serem bem sucedidos em seus papéis. A equipe, constituída por duas ou mais pessoas, pode incluir alunos, diretores, pais, professores especialistas em Educação Especial, professores de classe, psicólogos, terapeutas e supervisores (SCAFFNER; BUSWELL, 1999; BERSH, 2006).

No Rio de Janeiro, o Instituto Helena Antipoff(IHA), órgão da Secretaria Municipal de Educação, é o responsável pela elaboração e o acompanhamento de propostas que promovem o desenvolvimento da aprendizagem dos alunos com necessidades educacionais especiais.

O Atendimento Educacional Especializado (AEE) é desenvolvido, preferencialmente, na Sala de Recuso Multifuncional, mas pode ser complementado pelo trabalho do professor itinerante. Esse professor presta assessoria às escolas regulares com alunos incluídos e tem como função o acompanhamento de alunos e professores dentro da sala de aula regular, além de orientar a direção, outras equipes da escola, e os responsáveis pelos alunos.

Dentre os alunos com necessidades educacionais especiais, temos aqueles com deficiência física. Esses alunos podem apresentar dificuldades para andar, sentar, manter a cabeça posicionada adequadamente, falar, utilizar as mãos para segurar objetos ou escrever. Tais dificuldades podem envolver, ainda, o uso do computador sem adaptações e a realização de atividades de vida diária como ir ao banheiro com independência ou alimentar-se.

No processo de inclusão escolar das crianças com deficiência física, o uso da Tecnologia Assistiva se mostra essencial. A Tecnologia Assistiva, área de conhecimento que abrange recursos e serviços destinados a proporcionar maior qualidade de vida aos indivíduos com perdas funcionais advindas de deficiência ou como resultado do processo de envelhecimento, envolve áreas como: a Comunicação Alternativa e Ampliada; a mobilidade alternativa; o posicionamento adequado; o acesso ao computador; a acessibilidade de ambientes e as adaptações às atividades de vida diária, ao transporte, aos equipamentos de lazer e aos recursos pedagógicos (KING, 1999; BARNES; TURNER, 2001; BERSH; PELOSI, 2007).

A Tecnologia Assistiva contribui para proporcionar maior habilidade e autonomia na realização das atividades e, consequentemente, promover a inclusão social em uma vida mais independente. A Tecnologia Assistiva é uma área interdisciplinar constituída pela expertise de muitos profissionais como educadores, terapeutas ocupacionais, fonoaudiólogos, fisioterapeutas, psicólogos, enfermeiras, assistentes sociais, oftalmologistas, engenheiros, especialistas em audição, protéticos e, ainda, os usuários e seus familiares. As equipes são constituídas em função das necessidades do usuário e considerando as realidades do local onde está sendo desenvolvido o trabalho.

O trabalho do terapeuta ocupacional na Tecnologia Assistiva envolve a avaliação das necessidades dos usuários, suas habilidades físicas, cognitivas e sensoriais. $\mathrm{O}$ profissional avalia a receptividade do indivíduo quanto à modificação ou uso da adaptação, sua condição sociocultural e as características físicas do ambiente em que será utilizada. Ainda promove a instrução do uso apropriado do recurso de Tecnologia Assistiva e orienta as outras pessoas envolvidas no uso dessa tecnologia (CAOT-POSITION STATEMENT, 2003).

A especificidade do trabalho do terapeuta ocupacional na Tecnologia Assistiva envolve a ênfase que é dada na função, ou seja, na habilidade de realizar tarefas específicas em casa, na escola ou no ambiente educacional. A Tecnologia Assistiva possibilita ao terapeuta ocupacional estimular a função e reduzir a interferência da deficiência na realização de atividades funcionais de maneira independente. (SHUSTER, 1993).

Para que a Tecnologia Assistiva faça parte do dia-a-dia da escola é necessário que os profissionais que trabalham com os alunos sejam capazes de implementá-la. $\mathrm{O}$ trabalho em parceria entre professores de escolas públicas, terapeutas ocupacionais e o provimento de outros serviços de apoio aos estudantes com necessidades especiais têm sido considerados fundamentais no sistema educacional (BARNES; TURNER, 2001).

Esse tema constitui o objeto desse trabalho cujo objetivo foi verificar se a parceria entre os profissionais da Saúde e da Educação utilizando os recursos da Tecnologia Assistiva favorece o processo de inclusão escolar de alunos com quadro de paralisia cerebral incluídos nas escolas públicas do município do Rio de Janeiro. 


\section{Procedimentos metodológicos}

O projeto foi encaminhado ao Comitê de Ética em Pesquisa da Secretaria Municipal de Saúde do Rio de Janeiro e foi aprovado em 28/09/2004 com o protocolo CEP SMSRJ No 03/2004.

Participaram do estudo quatorze professores itinerantes, cinco terapeutas ocupacionais e três fonoaudiólogas que haviam recebido formação em serviço na área de tecnologia assistiva nos anos de 2005 e 2006 . A formação contou com um curso teórico-prático de 40 horas para cada um dos grupos e 10 meses de supervisão ofertada no ano seguinte, totalizando 80 horas para cada grupo. Além desses profissionais, foram sujeitos da pesquisa diretores das quatro escolas municipais selecionadas na cidade do Rio de Janeiro, quatro alunos com quadro de paralisia cerebral com idades entre 5 e 15 anos e seus familiares, quatro professores de turma e cinco professores de aulas complementares.

\section{Local e Instrumentos}

Os instrumentos para coleta de dados do pré-teste compreenderam entrevistas e questionários. Os professores itinerantes e os profissionais de Saúde responderam ao Instrumento 1 - "Questionário Inicial" contendo 76 perguntas abertas sobre o aluno, a escola, participação na sala de aula, conteúdo pedagógico, avaliação e atendimentos na área de saúde; os professores de aulas complementares responderam ao Instrumento 2 - "Questionário inicial aos professores de aulas complementares" contendo 18 perguntas abertas sobre o aluno e sua participação na aula, e os diretores das escolas ao Instrumento 3 - "Questionário inicial aos diretores" contendo 14 perguntas abertas sobre o aluno e sua participação na escola. Com as famílias e professores foram realizadas entrevistas semi-estruturadas.

O desenvolvimento do trabalho foi registrado através de fotografias, filmes, anotações realizadas pelas equipes de apoio e observações registradas no caderno de campo da pesquisadora.

Ao término do projeto foi realizado um follow up através de entrevistas semi-estruturadas com os alunos, familiares, professores de turma, professores itinerantes e profissionais de Saúde, que funcionou como pós-teste.

\section{PROCEDIMENTOS}

O método utilizado foi a pesquisa-ação. As escolas, nas quais foi implementada a intervenção, foram escolhidas pela coordenação do Centro de Referência em Educação Especial a partir de critérios como: presença de um ou mais alunos com deficiência física incluídos; alunos que necessitassem de recursos de comunicação oral e/ou escrita; alunos que necessitassem de orientações dos profissionais da Saúde; que estudassem no turno da manhã e alunos que estivessem sendo acompanhados por professores que participaram da formação em serviço.

Inicialmente foram realizadas as entrevistas e aplicação dos questionários aos diretores, professores de turma, professores de aulas complementares, familiares, professores itinerantes, fonoaudiólogos e terapeutas ocupacionais que acompanhavam os quatro alunos estudados. Os próprios alunos também foram ouvidos.

Foram formadas quatro equipes de apoio compostas por um terapeuta ocupacional, um fonoaudiólogo e um professor itinerante que participaram do trabalho conjunto nas escolas. Cada equipe esteve em sua escola de referência de quatro a seis vezes ao longo do ano de 2006, realizando intervenção direta junto ao aluno e provendo orientação ao professor de turma, aos professores das aulas complementares e aos funcionários da escola. Apenas a equipe de apoio do Aluno 1 não contou com uma fonoaudióloga, que se desligou da pesquisa por problemas pessoais.

As supervisões da ação conjunta realizadas pela pesquisadora ocorreram na escola onde o aluno estava incluído para que os professores e os funcionários pudessem participar das discussões e tivessem oportunidade de dar sugestões. A equipe de apoio permanecia na escola por quatro horas, tempo esse que era dividido entre a intervenção com os alunos na sala de aula e a supervisão com os profissionais fora da sala. Além das supervisões na escola foram realizados sete encontros fora do espaço educacional que consistiram em apresentações das intervenções das equipes e discussões com os demais membros do grupo.

\section{RESULTADOS}

Foram realizadas análises quantitativas das questões fechadas dos questionários e análise de conteúdo das questões descritivas dos questionários e das entrevistas. A técnica utilizada foi a de análise categorial, que funciona por operações de desmembramento do texto em categorias, segundo, reagrupamentos analógicos (BARDIN, 2009).

\section{Dados iniciais dos alunos colhidos através dos instrumentos do pré-teste}

O Aluno 1 tinha nove anos e quadro de paralisia cerebral do tipo atetóide. Seu quadro motor caracterizavase por uma impossibilidade de sentar em cadeira comum, manter-se de pé ou andar. $\mathrm{O}$ aluno não conseguia utilizar 
as mãos para pegar objetos ou escrever. Falava com muita dificuldade. A fala era lenta, baixa e de difícil compreensão. Estava alfabetizado, lia com boa compreensão de texto, soletrava as palavras que eram escritas por um amigo, pela professora ou familiares, não sendo capaz de escrever sozinho. Deslocava-se com o auxílio de uma cadeira de rodas e não era capaz de fazer isso de maneira independente. Estava incluído no $3^{\circ}$ ano, em uma sala com 28 alunos, e havia estudado nos dois anos anteriores na classe especial existente na própria escola. $\mathrm{O}$ processo de alfabetização foi realizado na classe especial, e o aluno foi preparado para ser incluído na turma regular.

O Aluno 2 era um rapaz de quinze anos com quadro de paralisia cerebral do tipo atetóide. Seu quadro motor caracterizava-se por uma impossibilidade de se manter sentado sem apoio, ficar de pé ou andar. Apresentava movimentos incoordenados em todo o corpo, mas, apesar da incoordenação motora dos membros superiores era capaz de apontar e pegar objetos com dificuldade. $\mathrm{O}$ aluno não falava ou escrevia. Era capaz de ler com boa compreensão de texto, mas a escrita com letras móveis encontrava-se no estágio silábico. Estava incluído no $5^{\circ}$ ano e sua trajetória escolar incluía a escola especial, uma classe especial para alunos com déficit intelectual e a inclusão na escola regular no $4^{\circ}$ ano. Estava cursando o $5^{\circ}$ ano pela segunda vez.

O Aluno 3 era um menino de 10 anos com quadro de paralisia cerebral do tipo diplegia espástica que não era capaz de andar ou permanecer de pé sem apoio. Utilizava uma cadeira de rodas para se deslocar e era capaz de movimentar sua cadeira em locais planos e por curtas distâncias. Era capaz de sentar na cadeira da escola sem adaptação, falava com muita desenvoltura, lia com dificuldade, mas não era capaz de escrever. Participava oralmente das atividades e utilizava letras e números móveis para realizar as tarefas, quando apoiado pela professora itinerante. Estava incluído no $4^{\circ}$ ano em uma sala com 29 alunos.

O Aluno 4 era um menino de 5 anos com quadro de paralisia cerebral do tipo tetraplegia atetóide que não era capaz de andar ou sentar sozinho. Utilizava as mãos com dificuldade e possuía muita incoordenação de movimentos. Era deslocado no colo ou em um carrinho de bebê sem nenhuma adaptação e permanecia nesse carrinho na sala de aula dificultando sua participação nas atividades. Apresentava estrabismo importante e estava aguardando cirurgia de correção. Falava poucas palavras e estava incluído no $1^{\circ}$ ano da Educação Infantil.

\section{Intervenção da equipe de apoio na área de Tecnologia Assistiva}

A análise dos dados dos instrumentos do pré-teste possibilitou a construção das áreas nas quais os alunos necessitavam de intervenções para facilitar sua inclusão escolar: adequação postural, recursos alternativos para comunicação oral, recursos alternativos para escrita e matemática, orientações e sugestões de atividades adaptadas aos professores de aulas complementares, auxílio ao professor de turma para adaptação das atividades escolares, encaminhamento para serviços de Saúde e adaptação das atividades de vida diária. Cada equipe buscou os recursos e as estratégias que considerou mais adequado para auxiliar a inclusão do aluno, a partir de suas necessidades, e da realidade da sala de aula. Participaram das decisões os familiares, os professores de turma, professores de aulas complementares, diretores e coordenadores, além da equipe de apoio.

Os recursos para adequação postural incluíram: colete de neoprene, adaptação de uma cadeira de madeira, adequação de um carrinho especial para crianças com paralisia cerebral, faixa de neoprene para manutenção da perna em flexão e assento anatômico. Os recursos alternativos para escrita envolveram: engrossadores de lápis e órteses para a manutenção do posicionamento do punho e dedos, caderno com pautas largas, máquinas de escrever, computador e um apontador de cabeça para permitir o acesso ao computador; os recursos alternativos para a comunicação oral compreenderam as pranchas de comunicação e um gravador utilizado como comunicador. Os recursos alternativos para as atividades de matemática envolveram: números imantados, ábaco adaptado, prancha de comunicação e máquina de calcular.

As adaptações para atividades de vida diária reuniram adaptações para a alimentação como: mesa acoplada a cadeira de rodas, prato com ventosa, colher torta, engrossador para o talher e copo adaptado com tampa. As orientações para as aulas complementares envolveram as atividades adaptadas de Educação Física e recursos adaptados para as atividades expressivas como o uso do apontador de cabeça adaptado com pincel.

A cada encontro ocorrido com intervalo de 45 dias ao longo do ano letivo, as estratégias e recursos foram avaliados pela equipe de apoio e novas metas foram estabelecidas.

Intervenção dos profissionais e familiares (Dados colhidos a partir do caderno de campo da pesquisadora que registrou as supervisões realizadas na escola e fora do espaço educacional)

A equipe de apoio ouviu os professores das aulas complementares, observou a dinâmica de suas aulas, as estratégias que estavam utilizando para favorecer 
a participação dos alunos e, em conjunto, buscaram alternativas para que os alunos pudessem participar de maneira mais autônoma.

As professoras itinerantes tiveram papel fundamental na formação e acompanhamento dos profissionais que trabalhavam na escola, na parceria estabelecida com a família e no treinamento quanto ao uso dos recursos.

As professoras de turma colaboraram na implementação dos recursos criando atividades que favoreceram sua utilização em sala de aula.

O terapeuta ocupacional fez sugestões quanto à adequação postural, ao uso de engrossadores para o lápis, à inibição do membro superior não dominante, ao uso de apontador de cabeça para teclar, pintar e virar a página do livro. O profissional ofereceu, ainda, estratégias para o professor relaxar o braço do aluno para a realização de atividades, indicou adaptações para atividades de vida diária como a de alimentação e realizou sugestões para os professores de Educação Física que incluíram o uso de bola de gás para jogos adaptados, brincadeiras com bola de meia, o uso de luva de feltro para "pegar" objetos envolvidos com velcro, jogo de bocha adaptado com uma caneleta para orientar a bola, pinos colocados na mesa da cadeira para serem derrubados, atividades dinâmicas na cadeira de rodas como "pique-pega" e "Coelhinho na Toca" e atividades no colchonete, onde o aluno pudesse estar fora da sua cadeira de rodas.

O fonoaudiólogo contribui com a seleção de vocabulário das pranchas de comunicação ensinou o sistema de símbolos e promoveu estratégias de interação utilizando a Comunicação Alternativa. Nas suas orientações sugeriu estratégias para o desenvolvimento da fala, percepção auditiva, leitura, escrita e o pensar utilizando a linguagem.

\section{Evolução dos alunos e professores e considerações dos profissionais da equipe de apoio e familiares (Dados das entrevistas do pós-teste)}

Ao término do ano letivo, as mudanças observadas em relação ao Aluno 1, de 9 anos, incluído na $3^{\circ}$ ano foram: a mudança de atitude do aluno e da família em relação ao envolvimento e compromisso com o espaço escolar, a redução do número de faltas a escola mesmo em dias de chuva; a adaptação de atividades em sala de aula para favorecer a participação do aluno por parte da professora de turma; o desenvolvimento de novas estratégias por parte da professora itinerante para auxiliar o treinamento dos recursos de tecnologia assistiva que haviam sido introduzidos como o apontador de cabeça, a máquina de escrever, o computador, o gravador e a calculadora. Ao término do ano o aluno continuava sem o atendimento no serviço de saúde por falta de vaga.

Quanto ao Aluno 2, de 15 anos, incluído no $5^{\circ}$ ano, a professora de turma passou a sentar-se ao seu lado para registrar as respostas dadas por ele através do apontar, lia os textos quando esses não estavam ampliados, disponibilizava a prancha de comunicação, e adaptava atividades para serem executadas na máquina de escrever. A professora itinerante considerou que o aluno teve excelente evolução na comunicação com a introdução da prancha, e que a mesma contribuiu para aproximá-lo dos amigos e da própria professora. A professora de turma se referiu à prancha de comunicação como um recurso fundamental e um cartão de apresentação para o aluno na sua mudança de escola no ano seguinte. A professora de turma sinalizou que apesar dos progressos na busca de recursos alternativos, o aluno continuava muito dependente para a realização das atividades, e que precisava de alguém para auxiliá-lo todo o tempo. Para usar a máquina de calcular, o ábaco, a máquina de escrever ou a prancha de comunicação necessitava de um parceiro. Na opinião da professora, a inclusão só funcionaria se o aluno tivesse a ajuda do professor itinerante todos os dias.

O ajuste postural com a substituição do assento anatômico, colocação de uma faixa para posicionar o quadril e troca do colete trouxeram a possibilidade do aluno permanecer em sala sem cair da cadeira e, também, viabilizou sua participação nas aulas de Educação Física, o que se configurou em um grande ganho na opinião das professoras.

Ao término do ano uma questão não havia sido resolvida e trazia preocupação a todos: qual seria o futuro escolar do aluno que já havia sido retido no $5^{\circ}$ ano, no ano anterior, e que no ano seguinte deveria seguir para o $6^{\circ}$ ano. As professoras itinerantes e de turma consideravam a dependência do aluno para a realização das atividades, a falta de comunicação oral, e as dificuldades com a matemática e a escrita, aspectos que necessitavam de maior mediação.

O Aluno 3, de 10 anos, incluído no $4^{\circ}$ ano, iniciou atendimentos na área de terapia ocupacional e fonoaudiologia com a freqüência de uma vez semanal, na Unidade de Saúde onde trabalhavam os terapeutas que compunham a sua equipe de apoio. A vaga na Unidade foi conseguida com a intervenção dos próprios terapeutas e o trabalho auxiliou a implementação das novas estratégias. O aluno evoluiu muito no decorrer do ano na opinião dos professores e da equipe de apoio. Conquistou a escrita manuscrita, que não era imaginada pela professora itinerante e pela professora de sala de aula, e ganhou a possibilidade de escrever utilizando uma máquina elétrica ou um computador.

O aluno esteve mais participativo ao longo do ano e feliz com suas conquistas, na opinião das professoras. 
A mãe declarou que não achava que ele fosse conseguir "escrever com a mão" e que estava muito orgulhosa dele. $\mathrm{O}$ aluno evoluiu na leitura com o trabalho desenvolvido com a fonoaudióloga na Unidade de Saúde, mas as dificuldades de percepção visual ainda preocupavam a equipe.

Ao término do ano, a adequação da postura na cadeira de rodas não tinha sido resolvida, pois o aluno necessitava de uma cadeira maior e a família não tinha recursos financeiros para adquiri-la. As Secretarias de Saúde e Educação não estavam fazendo a dispensação de cadeiras e a família resolveu tentar o auxílio com um político. A máquina de escrever elétrica, também, não tinha sido conseguida ao término do ano letivo.

O Aluno 4, de 5 anos, incluído na Educação Infantil estava muito mais bem posicionado na opinião das professoras e da equipe de apoio, após a intervenção. Vinha usando o carrinho adaptado, que foi conseguido pela equipe de apoio, para o deslocamento dentro da escola, na aula de Educação Física e na sala de aula. A cadeira de madeira, que foi adaptada pela equipe, estava sendo pouco utilizada em função da dificuldade que a professora de turma tinha de colocá-lo e retirá-lo de lá. O aluno vinha aumentando sua independência na alimentação. Estava comendo com o auxílio do prato com ventosa e da colher torta com o cabo engrossado. $\mathrm{O}$ copo com alça e tampa também tinha dado autonomia para beber líquido. A professora de turma, que acompanhava a alimentação diariamente, relatou que a mesa acoplada à cadeira estava sendo fundamental para o posicionamento do aluno na alimentação. Para as atividades gráficas, o aluno estava usando um engrossador de lápis e uma órtese de posicionamento de punho. No fim do ano letivo, o aluno não tinha retornado aos atendimentos no Posto de Saúde. A mãe disse que não tinha como levá-lo porque o transporte não chegava até lá.

\section{DISCUSSÃO}

A intervenção na escola explicitou questões como: a importância da avaliação do recurso mais adequado para o aluno considerando-se suas necessidades, a relevância do acompanhamento do recurso de Tecnologia Assistiva introduzido para o aluno, a importância das orientações ao aluno, familiares e professores, e a necessidade de sistematização do aprendizado através de atividades diversificadas.

Ficou claro para as equipes de apoio que não basta que os recursos de Tecnologia Assistiva estejam disponíveis para a escola, pois é necessário que uma equipe habilitada avalie, oriente e implemente esses recursos (SCAFFNER; BUSWELL, 1999; BERSH, 2006).

\section{Benefícios da introdução de recursos e serviços de Tecnologia Assistiva}

Os benefícios observados com a introdução da Tecnologia Assistiva podem ser exemplificados pelas mudanças observadas nos professores de turma, nos professores de aulas complementares, nos terapeutas, alunos e familiares.

As professoras de turma passaram a adaptar atividades em sala de aula para favorecer a participação do aluno, a adequar as tarefas para serem respondidas com o recurso alternativo de escrita, a buscar novas estratégias para atividades coletivas, a realizar a mediação da atividade com o aluno, a ler textos que não estavam adequadamente ampliados e a utilizar a prancha de comunicação porque haviam modificado sua atitude frente ao aluno. Tinham mais conhecimento sobre as necessidades e potencialidades dos alunos com necessidades educacionais especiais e sentiam-se amparadas pela equipe de apoio.

O trabalho se modificou positivamente e as professoras puderam perceber que os alunos poderiam participar de maneira mais ativa e com maior autonomia a partir da introdução de recursos de Tecnologia assistiva e de novas estratégias.

As professoras itinerantes também se envolveram no processo de maneira mais ativa. Desenvolveram novos materiais para auxiliar o treinamento dos recursos que foram implementados e deram continuidade às estratégias propostas. Na opinião dos professores itinerantes, o trabalho cooperativo confirmou que a inclusão é possível e que ela pode acontecer de maneira mais produtiva e menos angustiante.

Os profissionais da Saúde também se beneficiaram das ações conjuntas na escola, pois aprenderam sobre a estrutura escolar, reconheceram a possibilidade de uma nova área de trabalho, perceberam a possibilidade de maior desenvolvimento comunicativo das crianças com paralisia cerebral e reconheceram a importância de conhecer a realidade da criança, além do espaço terapêutico.

Os alunos mostraram-se mais confiantes e felizes com mais interesse em freqüentar e participar da escola. Em entrevista realizada com o Aluno 1, por exemplo, o aluno aconselhou as outras crianças que, como ele, estavam na escola e não conseguiam escrever, que acreditassem nessa possibilidade.

As famílias passaram a valorizar mais o espaço educacional ampliando o tempo de permanência do aluno na escola e modificaram sua crença na possibilidade de aprendizado do filho. A mãe do Aluno 3 assim se expressou: "Eu não acreditava que ele ia conseguir escrever com a mão. Estou orgulhosa porque ele já sabe escrever”. 
Os benefícios observados pelo uso dos recursos de Tecnologia Assistiva foram: o desenvolvimento de uma comunicação alternativa à fala; mudança de atitude do aluno com maior envolvimento e participação nas tarefas; aumento da auto-estima; melhor posicionamento na postura sentada dentro e fora da sala de aula; melhora na comunicação com a professora e maior proximidade com os colegas; maior participação nas aulas complementares como Educação Física e Artes; possibilidade de escrita autônoma; melhora na relação com a família; independência nas atividades de vida diária e participação nas atividades de lazer.

\section{Assistiva}

\section{Problemas com recursos e serviços de Tecnologia}

Os problemas encontrados no uso da Tecnologia Assistiva foram: a dificuldade de aquisição dos recursos e o custo dos mesmos. Esse dado deve ser compreendido dentro da realidade do município do Rio de Janeiro inserido em um país em desenvolvimento onde não há uma política de apoio à inclusão que compreenda o acesso facilitado por distribuição, isenção de impostos ou financiamento diferenciado dos recursos de Tecnologia Assistiva. Essas questões já vêm sendo discutidas e o Decreto 3.298 de 20 de dezembro de 1999, ao citar os recursos garantidos às pessoas com deficiência, inclui os equipamentos e materiais pedagógicos especiais para educação, capacitação e recreação da pessoa com deficiência (BERSH, 2006). O que é necessário é que o decreto seja cumprido.

As dificuldades encontradas nas ações conjuntas envolveram: a distância entre as Unidades de Saúde e a escola; a dificuldade de liberação dos profissionais da Saúde para a participação no projeto e outras ações de parceria com a Educação; as dificuldades interpessoais que ocorreram entre os profissionais da Saúde e Educação e tiveram que ser mediadas pela pesquisadora; o desconhecimento dos profissionais da Saúde dos serviços de Educação Especial oferecidos pela Secretaria Municipal de Educação; a falta de recursos materiais na escola, na Oficina Vivencial do Instituto Helena Antipoff e nas Unidades de Saúde.

\section{CONCLUSÃO}

O serviço de Tecnologia Assistiva oferecido pelas equipes de apoio que contavam com profissionais da área da Saúde e Educação favoreceu a inclusão escolar dos quatro alunos com quadro de paralisia cerebral estudados na medida que teve efeitos positivos na postura dos alunos em sala de aula, no desenvolvimento de estratégias alternativas de comunicação oral e escrita, favoreceu maior mobilidade dos alunos através do uso de cadeiras de rodas apropriadas e maior independência para as atividades do dia-a-dia escolar .

A parceria forneceu o apoio necessário para que os professores e os alunos fossem bem sucedidos em seus papéis. Contudo, é fundamental, que sua implementação ocorra em toda a rede de maneira sistemática para que o acompanhamento às estratégias e recursos implementados possam ser reavaliados e adequados sempre que necessário.

PELOSI, M. B.; NUNES, L. R. D. P. Health and education professionals partnership in inclusive education. Rev. Ter. Ocup. Univ. São Paulo, v. 22, n. 1, p. 52-59, jan./abr. 2011.

\begin{abstract}
The aim of this study was to assess whether the introduction of Assistive Technology favors the inclusion of students with cerebral palsy in four schools within the municipality of Rio de Janeiro (Brazil) when mediated by the joint action of professionals in Health and Education. Fourteen itinerant teachers, five occupational therapists, three speech pathologists, four school principals, four students with cerebral palsy, and their families, four regular school teachers, and five teachers from complementary classes participated in this study. An action-research design was implemented using questionnaires, interviews, participants' written records, photos, video recordings, and researcher's field notes. Four teams were formed consisting of occupational therapists, speech pathologists and itinerant teachers who had received training in the area of assistive technology. These professionals attended four to six meetings at the school and participated in seven supervisions outside of the educational space. The results of joint action included learning situations conducive to educational inclusion, awareness and attitude change of teachers, and closeness between teachers and students. The systematic use of assistive technology resources had a positive effect on the students' seating posture in the classroom; development of face to face and written communication; mobility through the use of appropriate wheelchairs; and independence in the daily school activities.
\end{abstract}

KEY WORDS: Occupational therapy; Cerebral palsy; Education, continuing 


\section{REFERÊNCIAS}

BARDIN, L. Análise de conteúdo. Tradução de Luís Reto e Augusto Pinheiro. Lisboa: Edições 70, 2009.

BARNES, K. J.; TURNER, K. D. Team collaborative practices between teachers and occupational therapist. The American Journal of Occupational Therapy, v. 55, n. 1, p.83-9, 2001.

BERSH, R. C. R. Tecnologia assistiva e educação inclusiva. Ensaios Pedagógicos. In: SEMINÁRIO NACIONAL DE FORMAÇÃO DE GESTORES E EDUCADORES, 3., 2006. Brasília: MEC/SEE, 2006. Disponível em: http://portal.mec.gov. $\mathrm{br} / \mathrm{seesp} /$ arquivos/pdf/ensaios\%20pedagogicos.pdf. Acesso em 3 fev. 2008.

BERSH, R. C. R.; PELOSI, M. B. Portal para ajudas técnicas. Tecnologia Assistiva: recursos de acessibilidade ao computador. Brasília: MEC/SEESP, 2007.

CANADIANASSOCIATION OF OCCUPATIONAL THERAPISTS POSITION STATEMENT. Assistive Technology and Occupational Therapy. The Canadian Journal of Occupational Therapy, v. 70, n.
2, p.113-118, 2003.

KING, T. W. Assistive technology - essential human factors. Boston: Allyn and Bacon, 1999.

MITTLER, P. Educação inclusiva: contextos sociais. Porto Alegre: Artmed, 2003.

PELOSI, M. B. Inclusão e tecnologia assistiva. v. 1, 2. $303 \mathrm{f}$. Tese (Doutorado em Educação) - Programa de Pós-graduação em Educação da Faculdade de Educação, Universidade do Estado do Rio de Janeiro, Rio de Janeiro, 2008.

SCHAFFNER, C. B.; BUSWELL, B. E. Dez elementos críticos para a criação de comunidades de ensino inclusivo e eficaz. In: STAINBACK, S.; STAINBACK, W. (Orgs.). Inclusão - um guia para educadores. Tradução de M. França. Porto Alegre: Artes Médicas Sul, 1999. p.69-87.

SHUSTER, N. E. Addressing assistive technology needs in special education. The American Journal of Occupational Therapy, v. 47, n. 11, p.993-997, 1993.

Recebido para publicação: 25/06/09

Aceito para publicação: 20/05/11 